\title{
PABLO MARTINEZ DEL RIO, 1892-1963
}

\author{
Alfonso Caso \\ English Translation by Rudolph C. Troike
}

El día 26 de enero último falleció en la Ciudad de México el Dr. Pablo Martínez del Río. En el momento en que lo sorprendió la muerte, era profesor de Historia Antigua y Director de la Escuela de Antropología, Director del Instituto de Historia de la Universidad Nacional y Director del Departamento de Prehistoria en la Escuela de Antropología, que él fundara en unión del Dr. Luís Aveleyra.

Había nacido en la Ciudad de México el 10 de mayo de 1892, siendo sus padres el abogado Pablo Martínez del Río y la señora Barbara Vinent. Realizó sus primeros estudios en México y luego los completó en los Estados Unidos y en Inglaterra, en el Colegio de Stonyhurst, en donde fué compañero de Dn. Manuel Romero de Terreros, actualmente Presidente de la Academia Mexicana de la Historia. Al terminar sus estudios en Stonyhurst, los continuó en el Colegio Oriel de la Universidad de Oxford, desde 1910 a 1914.

De sus estudios en Oxford obtuvo un perfecto dominio de la lengua inglesa y una francas vocación por el estudio de la cultura greco-latina y las antiguas civilizaciones del Oriente. Viajó extensamente por Europa y el norte de Africa y en el año de 1922, en un viaje que hizo a España, casó con doña María Josefa Fernández de Henestroza. La amenaza de la primera Guerra Mundial y preocupaciones por sus bienes que habian sufrido durante el período revolucionario, hicieron que don Pablo Martínez del Río tuviera que regresar al país sin haber obtenido sus grados en Europa. Su doctorado lo obtuvo en la Universidad Nacional.

En su Alma Mater fué profesor de diversas cátedras de Historia de México, principalmente en la Facultad de Filosofía, donde enseñó además Prehistoria, Historia Antigua e Historia Medieval. Más tarde, al fundirse el Departamento de Antropología de la Escuela Nacional de Ciencias Biológicas con la Sección de Antropología de la Facultad de Filosofía y Letras, y dar nacimiento ambas instituciones a la Escuela Nacional de Antropología, Pablo Martínez del Río fué designado Professor de Prehistoria y Protohistoria.

Se le nombró Director de la Escuela en 1944, y a la muerte de García Granados, en 1956,
On the 26th of January, 1963, Dr. Pablo Martinez del Río passed away in Mexico City at the age of 70. At the time of his death he was Professor of Ancient History and Director of the National School of Anthropology; Director of the Institute of History of the National University of Mexico and Director of the Department of Prehistory in the School of Anthropology, which department he founded together with Dr. Luís Aveleyra.

He was born in Mexico City on May 10, 1892, a son of the lawyer Pablo Martínez del Río and Barbara Vinent. His first studies were undertaken in Mexico and later completed in the United States and in England at Stonyhurst College, where he was the classmate of Don Manuel Romero de Terreros, now president of the Academia Mexicana de la Historia. After finishing at Stonyhurst, he continued his studies at Oriel College, Oxford, from 1910 to 1914.

From his studies at Oxford he acquired a perfect command of the English language and a profound interest in the study of Graeco-Latin culture and the ancient civilizations of the East. $\mathrm{He}$ traveled extensively through Europe and North Africa; and in 1922, during a trip to Spain, he married María Josefa Fernández de Henestroza. The threat of the First World War, and concern for his property, which had suffered during the revolutionary period in Mexico, forced Don Pablo Martínez del Río to return to his country without having received his degrees in Europe. He later took his doctorate at the National University of Mexico.

In his alma mater he held several chairs of Mexican history, principally in the Faculty of Philosophy, where he also taught prehistory, ancient history, and medieval history. Later, when the Department of Anthropology of the National School of Biological Sciences merged with the Anthropology Section of the Faculty of Philosophy and Letters, and these combined institutions gave rise to the National School of Anthropology, Pablo Martínez del Río was appointed Professor of Prehistory and Protohistory.

He was named Director of the School of Anthropology in 1944 and, on the death of Garcia Granados in 1956, Director of the Institute of History of the National University. For many 
Director del Instituto de Historia de la Universidad Nacional. Durante largos años fué también profesor de la Escuela de Verano, por lo que varios cientos de estudiantes norteamericanos recibieron sus enseñanzas del brillante profesor, que despertó en muchos de ellos la vocación para continuar con los estudios históricos. Fué distinguido con varias representaciones del Gobierno de México o de la Universidad, en reuniones de carácter cultural y fué Consejero de los Institutos de Relaciones Culturales Inglés y Norteamericano establecidos en México. Al morir era Miembro de la Academia Mexicana de la Historia, de la Sociedad Mexicana de Antropología, del Royal Anthropological Institute, de la American Anthropological Association y de la Société des Americanistes de Paris.

En 1944 Pablo Martínez del Río fué distinguido por la Universidad de Nuevo México con el grado de Doctor Honoris Causa, y en 1947 con el mismo grado en el Macalester College. Era Oficial de Instrucción Publica y Caballero de la Legión de Honor de Francia. Otro aspecto interesante de su vida fué su relación con instituciones bancarias y fundaciones de carácter benéfico.

La extensa obra de Martínez del Río, comprende múltiples libros y artículos sobre diversas materias que podrán verse en la Bibliografía que tomamos del Libro de Homenaje que se hizo en su honor el año de 1961, al cumplirse los 25 años de la primera aparición de Los Orígenes Americanos. Conviene resaltar además de esta obra, sus estudios sobre Tlatelolco, que fueron publicados en las Memorias de la Academia Mexicana de la Historia y su trabajo en la Cueva de la Candelaria, así como sus varios artículos sobre pinturas rupestres $\mathrm{y}$ petroglifos existentes in México.

Nos ocuparemos al final de esta nota del primer libro por su extraordinaria importancia, pero en Tlatelolco a través de los tiempos, que publicó desde 1944 hasta 1956, están condensadas muy importantes consideraciones sobre los descubrimientos y los trabajos arqueológicos e históricos que se iban realizando en esa zona, cuya organización fué el resultado de su interés y de su entusiasmo por resucitar esa ciudad gemela de Tenochtitlan. El otro trabajo muy importante que hemos señalado, sus estudios sobre la Cueva de la Candelaria, así como los del mamut de Sta. Isabel Ixtapan, lo colocaron como un excelente investigador de campo en materia prehistórica.

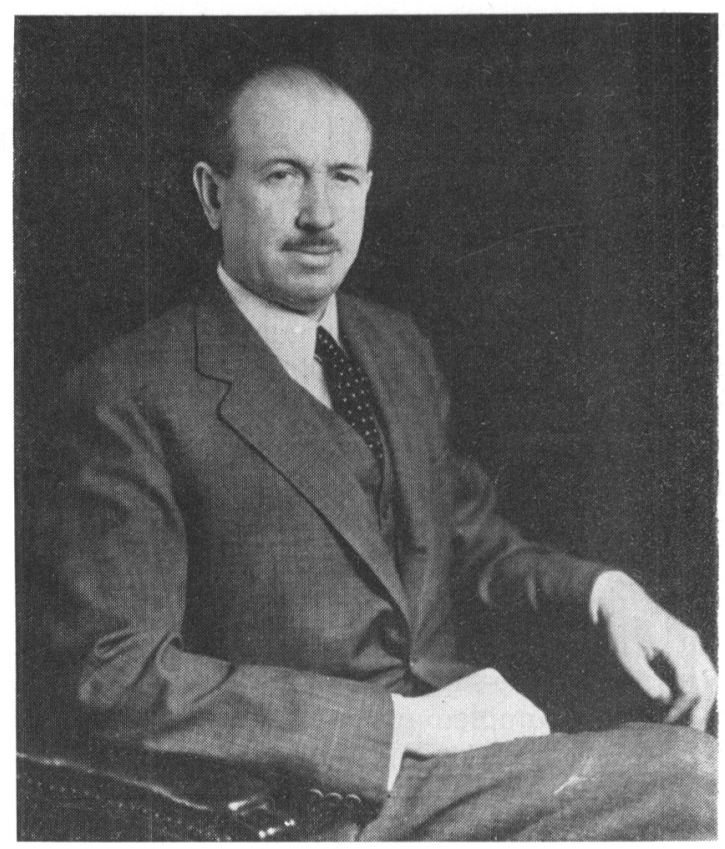

Pablo Martínez del Rio

years he was also on the faculty of the Summer School of the National University, where several hundred students from the United States received training from this brilliant professor who awakened in many of them a desire to continue their historical studies. He was honored by his selection as representative of the Government of Mexico or of the University at numerous meetings of a cultural nature, and he served as Adviser to both the English and American Institutes of Cultural Relations established in Mexico. At the time of his death he was a member of the Academia Mexicana de la Historia, the Sociedad Mexicana de Antropología, the Royal Anthropological Institute, the American Anthropological Association, and the Société des Americanistes de Paris.

In 1944 Pablo Martínez del Río was honored by the University of New Mexico with the degree of Doctor Honoris Causa and in 1947 with the same degree at Macalester College. He was also made an Officier de l'Instruction Publique and a Chevalier de la Légion d'Honneur by the French government. Another interesting aspect of his life was his connection with banking institutions and philanthropic foundations.

The extensive work of Martinez del Rio includes numerous books and articles on diverse subjects, as may be seen in the bibliography, 
Pero sin duda el libro más importante de los que debemos a su pluma, es el llamado Los Origenes Americanos. Este espléndido libro, más que un resumen de la Prehistoria del Nuevo Mundo y del origen de los americanos es, según creemos, el más importante manual, el más moderno y el mejor informado que tenemos sobre esta materia. La primera edición de Los Origenes Americanos, es de 1936, y ya condensaba en forma admirable los conocimientos que se tenían entonces sobre la Prehistoria de América. La objetividad con la que Martínez del Río describe las diversas teorías sobre el poblamiento del Continente; la erudición con la que acumula las pruebas de carácter somático, lingüístico, etnográfico y arqueológico, y la claridad con la que expone las diversas teorías, hacen que este libro sea indispensable, para el conocimiento de la Prehistoria del Nuevo Mundo. Creemos que la traducción en inglés de esta obra, sería realmente importante para dar una información de conjunto a los estudiantes de Prehistoria de habla inglesa.

Nuestra conexión con Dn. Pablo, como se le llamaba cariñosamente, fué no solo en el terreno científico, también en el terreno universitario y en el de la personal amistad. Nunca se podrá olvidar la magnífica ayuda que proporcionó en el Consejo Constituyente de la Universidad al elaborar la nueva Ley que la rige, cuando fuí designado Rector de esa Institución, y su cooperación honesta y objetiva, cuando fué designado para juzgar de supuestos hallazgos arqueológicos.

Pablo Martínez del Río era un concienzudo investigador y un intachable caballero, por lo que los antropólogos de México sentimos la pérdida de nuestro amigo y compañero no sólo por el vacío que deja en las instituciones que dirigía y en las cátedras que desempeñaba, sino por la alta calidad moral del desaparecido. Fué un honesto y bondadoso caballero, respetuoso de las ideas de los demás, y un amigo cordial y sincero. which is taken from the Libro de Homenaje prepared in his honor in 1961, on the 25th anniversary of the first publication of Los Origenes Americanos. Recognized as outstanding, in addition to this work, were his studies on Tlatelolco, which were published in the Memorias de la Academia Mexicana de la Historia, and his work on the Cueva de la Candelaria, as well as his various articles on pictographs and petroglyphs found in Mexico.

We will give further attention at the end of this note to the first-mentioned book because of its extraordinary importance. However, in Tlatelolco a través de los tiempos, which he published from 1944 to 1956, is condensed much important information about the discoveries and the archaeological and historical investigations which were being made at that site. The organization of these investigations was the result of his interest and enthusiasm for resuscitating the twin city of Tenochtitlan. The other important work that we have noted, his studies on the Cueva de la Candelaria, as well as those on the mammoth of Santa Isabel Ixtapan, establish him as an excellent field worker in prehistoric materials.

But without doubt the most important book among those that we owe to his pen is that entitled Los Origenes Americanos. This splendid volume - more than just a résumé of the prehistory of the New World and of the origin of its inhabitants - is, we believe, the most important, the most modern, and the best-informed handbook which we have on this subject. The first edition of Los Origenes Americanos was that of 1936, and it admirably condensed the then-existing state of knowledge regarding the prehistory of America. The objectivity with which Martínez del Río describes the diverse theories on the peopling of the continent; the erudition with which he accumulates the somatic, linguistic, ethnographic, and archaeological evidence; and the clarity with which he expounds the various theories make this book indispensable to an understanding of New World prehistory. We believe that an English translation of this work would be truly important for giving a complete source of information to English-speaking students of prehistory.

Our association with Don Pablo, as he was fondly called, was not only in the scientific field, but also in the University environment and in personal friendship. One can never forget the 
magnificent aid which he provided in the Constitutional Council of the University in working out the new law which governs it, when I was designated Rector of that institution; and his just and objective cooperation when he was called on to evaluate putative archaeological discoveries.

Pablo Martínez del Río was a conscientious investigator and an irreproachable gentleman. The anthropologists of Mexico regret the loss of our friend and companion not only because of the void he leaves in the institutions which he directed and in the positions which he held, but also because of his high moral quality. He was a just and kind gentleman, respectful of the ideas of others, and a cordial and sincere friend.

\section{Bibliografía de Pablo Martínez del Río}

\section{3}

Sebastián de Arteaga. Boletín de la Sociedad Mexicana de Geografía y Estadistica, quinta época, t. VI, núm. 11, pp. 532-5. México.

\section{4}

Arte antiguo mexicano: Sebastián de Arteaga. Arte y Letras, segunda época, t. I, núm. 4, sin paginación. M'éxico.

Los designios de los dioses. (Fantasía). La Nave, vol. 1, núm. 1, pp. 76-91. México.

Entierro bajo la luna. (Fantasía). Panorama Mundial. México.

Congreso de rectores. Universidad de México, t. I, núm. 1, pp. 72-3. México.

Traducción: Los pastores. Dorothy Hirsfield. Universidad de México, t. I, núm. 2, p. 156. México.

Conferencias de don Salvador de Madariaga. Universidad de México t. II, núm. 7, pp. 55-7. México.

Descubrimiento en Ur de los caldeos. Universidad de México, t. I, núm. 4, p. 356. México.

El cráneo de Pekin. Universidad de México, t. I, núm. 4, pp. 357-8. México.

El culto del Ka y sus consecuencias económicas. Universidad de México, t. I, núm. 6, pp. 526-7. México.

El doctor Millikan y la muerte del Universo. Universidad de México, t. I, núm. 5, pp. 440-1. México.

El Instituto Carnegie y el Templo de los Guerreros. Universidad de México, t. II, núm. 10, pp. 326-32. México.

El Oriente y la civilización occidental. La Universidad de Rabindranath Tagore. Universidad de México, t. I, núm. 6, p. 525. México.

En torno a la arqueología griega: ruina y destrucción de los monumentos antiguos. Universidad de México, $\mathrm{t}$. II, núm. 13, pp. 11-12. México.
Excavaciones en Kish. Universidad de México, t. I, núm. 5, pp. 441-2. México.

Ghirza: ciudad misteriosa del Sahara. Universidad de México, t. I, núm. 5, pp. 439-40. México.

Hallazgo de obras de arte en el Pireo. Universidad de México, t. I, núm. 5, p. 440 . México.

Investigaciones recientes sobre los aerolitos. Universidad de México, t. I, núm. 5, pp. 443-5. México.

Jeans y los misterios del cosmos. Universidad de México, t. I, núm. 3, pp. 244-6. México.

Joyas y tesoros de la Alta Edad Media. Universidad de México, t. I, núm. 5, pp. 407-18. México.

Los nuevos museos de Berlin. Universidad de México, $\mathrm{t}$. II, núm. 7, p. 70. México.

Los orígenes de la civilización maya. Universidad de México, t. I, núm. 4, p. 356 . México.

Los rayos cósmicos. Universidad de México, t. II, núm. 7, p. 70. México.

Arreglo: México Desconocido: Las Monterías de Chiapas, por Rodulfo Brito Foucher. Universidad de Mexico, t. I, núm. 4, pp. 323-30. México.

Nuevas excavaciones en Ur de los caldeos. Universidad de México, t. II, núm. 7, pp. 69-70. México.

Travesía de la Peninsula Arábica. Universidad de México, t. I, núm. 6, pp. 525-6. México.

Una joya del arte colonial a punto de desaparecer. Universidad de México, t. I, núm. 5, p. 520. México.

Traducción: Un personaje del Marruecos viejo: el Cherif Raisuni, por Robert Ricard. Universidad de México, $t$. I, núm. 5, pp. 382-7. México.

1932

Nota bibliografica: Acapulco en la historia y la leyenda, por V. Alessio Robles. Universidad de México, t. IV, nums. 21-22, pp. 370-1. México.

A propósito de los descrubrimientos de Monte Albán. Universidad de México, t. III, núms. 17-18, pp. 518-20. México.

El horizonte de la Historia. Síntesis, t. II, núm. 7, pp. 172-5. M'éxico.

Nota bibliografica: El origen y la evolución de la vida, por H. F. Osborn. Universidad de México, t. IV, núms. 21-22, p. 370 . México.

Nota bibliografica: La ciudad arqueológica del Tajin, por E. J. Palacios y E. Meyer. Universidad de México, t. IV, núm. 20, pp. 206-07. México.

Nota bibliografica: L'incorporation de l'Indien par l'École au Mexique, por Robert Ricard. Universidad de México, t. IV, núm. 20, p. 206. México.

Sobre el horizonte de la Historia. Universidad de México, t. III, núm. 15, pp. 281-96. México.

Traducción: Juárez, Maximiliano y Palmerston, por Philip Guedella. Universidad de México, t. V, núms. 29-30, pp. 283-90. México.

Los cazadores del mamut. El Libro y el Pueblo, t. IX, núm. 2, pp. 52-8. México.

Temas recientes de Prehistoria y Arqueología. Universidad de México, t. V, núms. 27-28, pp. 256-68. México. 
1934

Les chasses "Chacu" au Mexique et les ruines du Zacatepec. Journal de la Société des Americanistes, n. s., t. XXVI, pp. 293-300. Paris.

Notas de numismática de la época de la Independencia. Anales del Museo Nacional de Arqueología, Historia y Etnografía, quinta época, t. I, núm. 3, pp. 479-84. México.

La primera ascensión al Cerro Blanco de Covadonga. Boletin de la Sociedad Mexicana de Geografía y Estadistica, t. XLV, núms. 3-4. pp. 199-209. México.

\section{6}

Los orígenes americanos. Porrúa Hermanos y Compañía. 278 pp. México.

Manuel Guillermo Lourdes, painter and draughtsman. Modern Mexico, vol. 8, núm. 7, pp. 6-9. Nueva York.

\section{7}

Alumbrado. Porrúa Hermanos y Compañia. 197 pp. México.

Aquines o el burlador burlado. Hoy, vol. IV, núm. 48, p. 21; núm. 49, p. 34. México.

Askesis. Letras de México, núm. 23, p. 3. México.

Dominus illuminatio mea. Lectura, t. IV, núm. 1, pp. 32-44. México.

Don Luis de Carvajal y los corsarios. Lectura, t. III, núm. 4, pp. 328-42. Mexico.

El diluvio, acontecimiento historico. Lectura, t. III, núm. 3, pp. 239-56. México.

El suplicio del hacendado. Editorial Polis. 72 pp. México.

Las dolencias del planeta y cómo influyen sobre la humanidad. Sintesis, vol. XIV, núm. 79, pp. 166-74. México.

Las familias más antiguas de Europa. Sintesis, vol. XV, núm. 84 , pp. 116-17. México.

La tregedia del Matterhorn. Más, núm. 6. México.

Ültima Thule. Universidad de México, t. V, núm. 27, pp. 27-8. México.

Un "Cuauhxicalli" germánico. Investigaciones Históricas, t. I, núm. 1, pp. 30-5. México.

Celerino el Justiciero. Hoy, año 11, vol. X, núm. 123, p. 82.

La domesticación del maíz y el problema de la antigüedad del hombre en América. Revista de la Universidad de la Habana, año IV, núm. 22, pp. 38-48. La Habana.

Mi amigo Celerino. Hoy, año 11, vol. IX, núm. 117, pp. 38-9. México.

Por la ventana de la Prehistoria. Editorial Polis. 128 pp. México.

The antiquity of maize cultivation in America. Actas del Vigésimoséptimo Congreso Internacional de Americanistas, t. I, pp. 92-5. México.

¿Un animal que discurre? Sintesis, vol. XVI, núm. 90, pp. 130-2. México.

1940

Los melanesios y polinesios en América. Revista de Estudios Universitarios, t. I, núm. 5, pp. 603-15. México.

\section{2}

Ola Apenes. Revista de Estudios Antropológicos, t. VI, núm. 3, pp. 177-80. México.
1943

Ante la Inquisición. Diqulgación Histórica, año IV, núm. 5, pp. 266-72. México.

La aventura mexicana de sir John Hawkins. Memorias de la Academia Mexicana de la Historia, t. II, núm. 3, pp. 241-95. México.

Los orígines americanos. Segunda edición (en realidad un libro nuevo). Editorial ARS. $368 \mathrm{pp}$. México.

\section{4}

Descubrimiento del Templo Mayor de Tlatelolco. Noticias de México. Boletín del Departamento de Información para el Extranjero, año IV, núm. 101, pp. 9-11. Secretaría de Relaciones Exteriores. México.

La aventura mexicana de sir John Hawkins. Intercambio (organo de la British Chamber of Commerce), núm. 7, pp. 24-6; núm. 8, pp. 24-5; núm. 9, pp. 42-5. México.

Las pinturas rupestres del Cerro Blanco de Covadonga, con algunas notas sobre la comarca circunvecina. Anales del Museo Nacional de Arqueologia, Historia y Etnografia, quinta época, t. I, núm. 1, pp. 43-66. México.

Nota preliminar. En Tlatelolco a través de los tiempos 1 . Sobretiro de las Memorias de la Academia Mexicana de la Historia, t. III, núm. 2, pp. 5-20. México.

Nota preliminar. En Tlatelolco a través de los tiempos II. Sobretiro de las Memorias de la Academia Mexicana de la Historia, t. III, núm. 4, pp. 5-8. México.

Panorama prehistórico. En El Norte de México y el Sur de Estados Unidos, pp. 157-62. Editorial Stylo. México.

Resumen. En Tlatelolco a través de los tiempos I. Sobretiro de las Memorias de la Academia Mexicana de la Historia, t. III, núm. 2, pp. 75-7. México.

Resumen de los trabajos arqueológicos. En Tlatelolco a través de los tiempos II. Sobretiro de las Memorias de la Academia Mexicana de la Historia, t. III, núm. 4, pp. 31-6. México.

\section{5}

La resurrección de Santiago Tlatelolco. Nosotros, vol. I, núm. 16, pp. 42-4. México.

Nota preliminar. En Tlatelolco a través de los tiempos III. Sobretiro de las Memorias de la Academia Mexicana de la Historia, t. IV, núm. 1, pp. 5-7. México.

Nota preliminar. En Tlatelolco a través de los tiempos VI. Sobretiro de las Memorias de la Academia Mexicana de la Historia, t. IV, núm. 4, pp. 5-6. México.

Notas preliminares. En Tlatelolco a través de los tiempos $V$. Sobretiro de las Memorias de la Academia de la Historia, t. IV, núm. 3, pp. 5-10. México.

Resumen de los trabajos arqueológicos. En Tlatelolco a través de los tiempos III. Sobretiro de las Memorias de la Academia de la Historia, t. IV, núm. 1, pp. 18-20.

Resumen de los trabajos arqueológicos. En Tlatelolco a través de los tiempos IV. Sobretiro de las Memorias de la Academia Mexicana de la Historia, t. IV, núm. 2, pp. 16-19. México.

Resumen de los trabajos arqueológicos. En Tlatelolco a través de los tiempos VI. Sobretiro de las Memorias de la Academia Mexicana de la Historia, t. IV, núm. 4, pp. 16-18. México.

\section{6}

En México Prehispánico, ed. Emma Hurtado: Arte y literatura, pp. 48-54; El poblamiento primitivo de América, pp. 3-9; Política y religion, pp. 55-60; Estudio comparativo y cultural material, pp. 39-47. México.

Notas preliminares. En Tlatelolco a través de los tiempos VII. Sobretiro de las Memorias de la Academia Mexicana de la Historia, t. V, núm. 2, pp. 5-7. México. 
Notas preliminares. En Tlatelolco a través de los tiempos VIII. Sobretiro de las Memorias de la Academia Mexicana de la Historia, t. V, núm. 4, pp. 5-8. México.

Resumen de los trabajos arqueológicos. En Tlatelolco a través de los tiempos VII. Sobretiro de las Memorias de la Academia Mexicana de la Historia, t. V, núm. 2, pp. 29-33. México.

\section{7}

El hombre fósil de Tepexpan. Cuadernos Americanos, vol. XXXIV, núm. 4, pp. 139-50. México.

En torno a la arqueología griega: ruina y destrucción de los monumentos antiguos. Universidad de México, vol. II, núm. 13, pp. 11-12. México

Nota preliminar. En Tlatelolco a través de los tiempos IX. Sobretiro de las Memorias de la Academia Mexicana de la Historia, t. VI, núm. 2, pp. 5-6. México.

The pathos and humour of early Mexican independent history. Macalester College Bulletin.

\section{8}

Notas preliminares. En Tlatelolco a través de los tiempos $\chi$. Sobretiro de las Memorias de la Academia Mexicana de la Historia, t. VII, núm. 2, pp. 5-7. México.

Por los atajos de la Ëlida. Ābside, vol. XII, núm. 2, pp. 219-27. México.

\section{9}

Apuntes sobre los substratos lingüísticos cantabro-alpinos: La base Nar. Memorias de la Academia Mexicana de la Historia, t. VIII, núm. 3, pp. 216-31. México.

Nota bibliografica: Flute of the smoking mirror, por Frances Gillmor. Arizona Quarterly, t. V, núm. 3, pp. 285-6. Tucson.

Contribuciones a: Last Chance, edited by Clara Urguhart, pp. 39-44, 72, 82, 91, 151. Boston.

Lo que M'éxico debe a Eduardo Seler. El México Antiguo, t. VII, pp. 22-4. México.

\section{0}

Vino nuevo para los odres viejos de la historia nacional. Memorias de la Academia Mexicana de la Historia, $t$. IX, núm. 2, pp. 195-8. México.

\section{1}

El archivo de don Porfirio. Tiempo, vol. XIX, núm. 485, pp. 33-34. México.

El cuadrilátero vital en la prehistoria del Viejo Mundo. Memorias de la Academia Mexicana de la Historia, $\mathrm{t}$. $\mathrm{X}$, núm. 3, pp. 277-84. México.

Elogio de Xalapa. Diario de Xalapa, 24 de julio, suplemento especial, p. 3, col. 4; p. 4, col. 4; y 25 de julio, suplemento especial, p. 3, col. 3; p. 4, col. 2. Xalapa.

La Real y Pontificia Universidad de México. Bosquejo histórico. Cuadernos Americanos, vol. IIX, núm. 5, pp. 141-69; en Ensayos sobre la Universidad de México, ediciones del IV Centenario de la Universidad de México, pp. 7-45. México.

Tylor in México. En Homenaje al doctor Alfonso Caso, pp. 263-70. Instituto Nacional de Antropología e Historia, México.

Una carta. Historia Mexicana, vol. I, núm. 2, pp. 335-9. México.

\section{2}

El mamut de Santa Isabel Iztapan. Cuadernos Americanos, vol. LXIV, núm. 4, pp. 149-70. México.

Los origenes americanos. Tercera edición. Editorial ARS. 451 pp. México.
1953

A preliminary report on the mortuary cave of La Candelaria, Coahuila, Mexico. Bulletin of the Texas Archeological Society, vol. 24, pp. 208-52. Austin.

Elogio de Jalapa. Huastecos, totonacos y sus vecinos. Re vista de Estudios Antropológicos, t. XIII, núms. 2-3, pp. 19-25. México.

La Cueva mortuario de la Candelaria, Coahuila. Cuadernos Americanos, vol. LXIX, núm. 4, pp. 177-204. México.

Los albores del Neolítico en el Cercano Oriente. Mer morias de la Academia Mexicana de la Historia, t. XII, núm. 4, pp. 279-85. México.

Los arios o indoeuropeos primitivos y sus enigmas. Universidad (Organo de la Universidad de Nuevo León), núm. 11, pp. 63-107. Monterrey.

\section{4}

La comarca lagunera a fines del siglo XVI y principios del XVII. Instituto de Historia, Universidad Nacional Autónoma de México. Editorial Jus, S. A. 124 pp. México.

Nota bibliografica: Origenes, por Hannah M. Wormington. Ciencias Sociales, vol. V, num. 25, pp. 16-21. Unión Panamericana, Washington.

\section{5}

Un arte de escribir del siglo XVIII. Apuntes para la historia del rasgueado en México. Instituto de Historia e Instituto de Investigaciones Estéticas, Universidad $\mathrm{Na}$ cional Autónoma de México. Imprenta Nuevo Mundo, S. A. México.

\section{6}

(Con Luís Aveleyra Arroyo de Anda y Manuel Maldonado-Koerdell) Cueva de la Candelaria. Instituto Nacional de Antropología e Historia. México.

Notas preliminares. EnTlatelolco a través de los tiempos XII. Sobretiro de las Memorias de las Academia Mexicana de la Historia, t. XV, núm. 2, pp. 109-10. México.

\section{7}

Algunas fechas recientes del C14 y su trascendencia para la etnohistoria de América. Memorias de la Academia Mexicana de la Historia, t. XVI, núm. 2, pp. 149-56. México.

Traducción: Tajin. Official Guide. Instituto Nacional de Antropología e Historia. Edimex. 31 pp. México.

Traducción: Tula. Official Guide. Instituto Nacional de Antropología e Historia. Edimex. 46 pp. México.

\section{8}

Nota bibliografica: Ancient Man in North America, por H. Marie Wormington. American Journal of Archae. ology, vol. 62, pp. 457-8. Ann Arbor.

Traducción: Monte Alban. Official Guide. Instituto Nacional de Antropología e Historia. Edimex. 38 pp. México.

\section{9}

Traducción: Maya Cities. Offrcial Guide. Instituto Nacional de Antropología e Historia. Imprenta Nuevo Mundo, 80 pp. México.

Respuesta de académico, doctor don Pablo Martínez del Río (al discurso de recepción del licenciado don Jorge Gurría Lacroix, como miembro de la Academia Mexicana de la Historia). Memorias de la Academia Mexicana de la Historia, t. XVIII, núm. 3, pp. 221-3. México. 
1960

Traducción: Calixtlahuaca. Official Guide. Instituto Nacional de Antropología e Historia. Edimex. 31 pp. México.

Traducción: Castle of Chapultepec. Official Guide. Instituto Nacional de Antropología e Historia. Edimex. 97 pp. México.

Traducción: Palenque. Official Guide. Instituto Nacional de Antropología e Historia. Edimex. 75 pp. México.

\section{1}

Prologo: Homenaje a Rafael Garcia Granados. Instituto Nacional de Antropología e Historia. pp. 7-10. México.
Sin Fecho

Traducción: Huexotzingo. Official Guide. Instituto $\mathrm{Na}$ cional de Antropología e Historia. 32 pp. México.

Traducción: Teotihuacán Official Guide. Instituto Nacional de Antropología e Historia. 32 pp. México.

This bibliography, which was compiled by Manuel Maldonada Koerdell and Guadalupe Borgonia, appears in a different form in Homenaje a Pablo Martínez del Rio en el XXV aniversario de la edición de Los Orígines Americanos (Instituto Nacional de Antropologia e Historia, México, 1961, pp. 23-28).

México, D. F.

9 de Mayo de 1963 